\title{
Competitive Remix Practice and Networks of Support in Electronic Dance Music Economies
}

\author{
$\bullet$ Feature Article $\longrightarrow$ \\ JONATHAN KARPETZ \\ MCGILL UNIVERSITY (CANADA)
}

\begin{abstract}
The rapid development and dissemination of social media fueled competition platforms has led to immediate shifts in the practices of creative workers in fields related to contest offerings. In Electronic Dance Music (EDM), crowdsourced competitive remix platforms have reoriented certain practices into networks of competition, where winning distinction is often only part of a larger process of further enmeshing DJs, music producers and their supporters in the social media fueled ecosystems that these websites have created. In order to begin to analyze the impact of remix competitions on producers and their personal and professional networks, I intend to trace a line of recent history and debate to reveal the connections linking EDM websites, labels, marketers, DJs, producers and supporters and their engagement with remix competition platforms. I will examine the call for support that is involved in so much of socially networked EDM communication between contestants and their peers surrounding these remix contests.
\end{abstract}

KEYWORDS: creative economies, crowdsourcing, competitive labour, remix, DJ, producer

Jonathan Karpetz is a first year PhD student in Communications at McGill University. He also is a "working" DJ with expertise in House and Top 40. Jonathankarpetz.com. Twitter: @jonathankarpetz

Dancecult: Journal of Electronic Dance Music Culture 6(2): 22-41 ISSN 1947-5403 @2014 Dancecult http://dj.dancecult.net DOI 10.12801/1947-5403.2014.06.02.02 dancecult 


\section{INTRODUCTION}

The contemporary remix contest finds its origins in the social media fueled club and bar networks that have grown around the introduction and adoption of low cost digital music production, performance and distribution technologies since the early to mid-2000s. ${ }^{1}$ Creative competition platforms emerged out of crowdsourcing and social media practices and technologies that began to mediate creative competitions by offering forums for the dissemination and tracking of remix contests for brands, labels, clubs, promoters, DJs and producers (Howe 2008; Brabham 2013). ${ }^{2}$ Websites including Indaba Music, Talenthouse. com, Wavo.me along with Beatport Play all aimed to engage "creative communities" in competition for opportunities to collaborate with major artists and brands and win prizes or employment. ${ }^{3}$ These platforms were fueled by the connections enabled through the highly developed social media APIs and protocols provided by Facebook, amongst others. ${ }^{4}$ Competitions appearing on these sites ranged from opportunities to make official videos for major artists, including Moby, Afrojack and the Flaming Lips, to an opportunity to photograph for the Thomson Reuters Foundation and Nokia, or remix a track for Tegan \& Sara to be released by Warner music (Beatport 2013c; Genero.tv 2013; Talenthouse Inc. 2013). While these platforms continue to invite a wide range of creative workers to submit to various competitions, my focus here is on the remix contests offered by these sites. These contests are aimed at DJs and producers and engage their personal and professional networks in regular competitions to rework provided audio samples or stems with the promise that the winner will be able gain a release of their remix on the contest provider's label and/or gain a chance to perform as an opening act for a major artist. ${ }^{5}$

Contemporary remix competition websites match established crowdsourcing practices of providing a platform for forming a crowd to solve creative problems, while also pushing the undercurrent of competition that drives most crowdsourcing initiatives to the forefront. They do this by encouraging the crowd's crowd to interact with their websites through social media by allowing the sharing, liking and voting of these contests by anyone who wishes to participate. While creative crowdsourcing is nothing new and creative contests were attempted in the early days of web-based crowdsourcing, these companies have developed neutral platforms that do not aim to solve significant creative or technical problems. ${ }^{6}$ Instead the sites offer creative competitions for partner corporations and related brands in the hopes of engaging a crowd of emerging artists and their audiences to produce creativity under the promise of prizes and exposure. By providing the solution the crowdsourcing platforms also help their partner brands achieve a wider reach via social media websites by transmitting competitions and integrating the submission, voting and judging processes across major social media websites. By facilitating competitions, creative platforms produce not only crowdsourced creativity but a deeper engagement sponsoring brands and creative networks with every like, share, or vote.

I will pursue my research guided by the following questions. 1. How has the introduction of music remix competitions, facilitated by web platforms through partnerships with major 
electronic dance music (EDM) labels, producers and brands, affected local DJ and producer communities and their organizing and performance practices? 2. Further, how are creative contests enabled through tensions between the dual roles many DJs and producers inhabit as both entertainers and artists? 3. Finally, how do discourses of support serve to drive engagement with these contests? I will study social media fueled remix competitions through the prism of contemporary scholarship on issues of labour and precarity in creative and "do it yourself" economies (Ross 2009; Standing 2011; Stahl 2012; Baker and Hesmondhalgh 2013; McRobbie forthcoming). As I will show, Contemporary DJs and producers are continually asked to engage with various remix contest platforms and their stakeholders as part of their day to day practice. It is the hidden nature of competitive crowdsourced remix labour, despite the very public nature of the calls for support that accompany the practice, that makes these practices a distinct case of work that needs to be addressed on its own terms.

In order to analyze the impact of remix competitions on producers and their personal and professional networks, it is important to trace a line from recent history and debate to reveal the connections linking local EDM networks and their engagement with social media fueled contest websites and their backers. In order to find these connections I intend to follow remix producers and their web of socially networked connections. Specifically, I examine the call for support that is involved in so much of socially networked EDM communication. By following notions of support I will begin to reveal the ideologies and discourses that bubble beneath the surface of professional dance music practices and how they allow for and rationalize these competitive remix practices.

My investigation of contemporary remix contests enabled through crowdsourced competition platforms grew out of a program of "insider ethnography" undertaken between August 2012 and March 2014. I drew guidance from Ed Montano's "industry based analysis" in Sydney's commercial club scene, situating the DJ and producer at the centre of my research $(2009,2010,2011,2013: 114)$. As a working DJ and as a participant in club and web based creative competitions, I was able to gain critical insight into systems of ideas and discourses that motivate local clubs, labels, DJs and producers to engage with remix competition platforms. The analysis that follows taps into my own networks of people, places and technologies that inform my DJ practice. Any discussion of these networks then is informed by some level of reflexivity about my work in nighttime economies, my interactions with other DJ actors, and my own entrance into the proliferation of social media-based contests that have arisen over the last many years. As with Montano, I occupied multiple positions in my research as both an "insider" DJ and as an "outsider" researcher (Montano 2013: 115). My engagement with these contests stemmed from both scholarly pursuits and creative interests, understanding full well I would confront and have to manage many of the issues and debates that have evolved out of contemporary competitions that I detail below. If claims about contemporary DJ contests seem vague, I hope that my situation within current DJ networks will develop productive knowledge of the issues at hand to lend voice to those most affected in hopes of an eventual escape from labour precarity. ${ }^{7}$ 


\section{Contemporary DJ and Producer labour}

The engagement of DJs and producers on social media fueled competition platforms has grown out of the many crises creatives in EDM networks have had to confront in their everyday practice. Traditional distinctions between the performative practice of DJing and the activities of bedroom or studio production has blurred with the rapid adoption of DVS and MIDI based performance and production equipment that encourages live production and remix. ${ }^{8}$ While DJing and music production are in many ways distinct practices, club owners and promoters often expect DJs to produce as a way of promoting their live performances, while EDM producers are expected to be competent DJs as their main access to stable income is through touring clubs and festivals as performers. Competition platforms have accelerated the merging of production and DJ practices, often offering performance-based rewards for competition winners. Success as a producer on these platforms is associated with becoming the next "superstar DJ", while DJs are encouraged to produce as a way of gaining access to exciting performances offered by the contests. What matters in contemporary creative networks is that contemporary DJs and producers are often engaged in competition platforms either as a way of gaining exposure for their original music productions or remixes or for promoting their roles as performers in local scenes.

In contemporary dance music economies the production of original EDM recordings and remixes are the result of a complex mode of production, often involving local producers and clubs, as well as local or internationally run labels. For established producers remix opportunities might be handed down from larger labels, either as paid work or as opportunities for "exposure", with promises of residual compensation depending on how the remix sells. Working producers circulate between smaller and more established labels, either as featured artists or as label owners themselves, often providing remixes for other producers, who themselves may be label owners or manager, with the promise that those artists will someday collaborate or remix in return. Across the music industry, labels and established artists turn to remixes as a way of promoting or expanding the reach of the original single. With the expansion of labels and releases on EDM focused download sites, such as Beatport, Tracksource and Trackitdown, in recent years remixes by established producers are no longer any guarantee that a track will reach the level of desired exposure, while the costs of inviting working producers to remix tracks may cost more than it is worth. As a result, clubs, labels and established producers have turned to a new form of remix production, the contemporary crowdsourced remix contest, as a way of enlisting young and enthusiastic producers in remixing their products but also in marketing their releases through the tools provided by competition platforms. DJs or producers looking for work are often directed to create mixes, remixes or produce new EDM tracks, which are then uploaded to these platforms as a showcase of their "unique" talent. These practitioners are then asked and often required to pass their creativity through their socially networked connections to gain likes or votes, which directly impact their chances of winning contests and finding work either as local DJs or as EDM producers. 
The rise of competitive labour in creative industries is a result of developments in technological and work related practices that have resulted in new sorts of creative subservience. Andrew Ross has observed that changes in labour practices invite a "condition of social and economic insecurity... which not only gives employers leeway to hire and fire workers at will, but also glorifies part-time contingent work as 'free agency', liberated from the stifling constraints of contractual regulations" (2009: 40). Angela McRobbie argues, "the flamboyantly auteur relation to creative work that has long been the mark of being a writer, artist, film director or fashion designer is now being extended to much wider section of a highly 'individuated' workforce” (2002: 517). Free agency and individuation has rolled into notions of "Me Inc"., or what Alison Hearn describes as the "branded self": "a distinct kind of labour; involving an outer-directed process of highly stylized self-construction, directly tied to the promotional mechanisms of the post-Fordist market" (2008: 201).

Notions of self-branding also are tied to what Joshua Gamson observes as the rise of the "ordinary celebrity" (2011: 1062). Exhibits of ordinary celebrity can be found in all forms of media, from reality and talent television shows, such as American Idol and The Voice, to the introduction of web-generated celebrity production platforms (Gamson 2011: 1065). The introduction of crowdsourced platforms for contestation is a further development of the externalization of labour costs by requiring participants to fund their creative projects in the hopes that they will win the contest and the attached prizes, which are often lump sum honorariums or vague promises of exposure. While performance-based competitions such as Battle of the Bands, Star Search and American Idol are not new, the contemporary mode of DJ contests, which include local contests and web-based remix contests, have produced and reflected a new form of work that asks DJs and producers to continually "labour to compete". The effect is a turning inwards of creative rhetoric and practice where DJs and producers continually compete with each other over what precious little work is available, while also providing libraries of free music remix content and networks of engaged fans to crowdsourced contest platforms instead of contesting the overriding labour practices maintained by club, music distribution and remix platforms that have challenged traditional practice.

\section{RHETORIC AND IDEOLOGY}

Research into how entertainers and artists deploy certain ideologies in their rhetoric has revealed that many working in creative economies are reluctant to implicate themselves in market practices despite their explicit association with capital in their day to day activities. Rosa Reitsamer's empirical research of DJs in Vienna, Austria in the late 2000s noted that "changing relations between culture and society and between art and money, associated with neoliberal economics and post-Fordist models of industry increasingly force cultural producers to adopt an entrepreneurial position", a position "reflected in the self-(re) presentations of the DJs" (2011:29). For Reitsamer, the DJs operate with art and money in 
opposition, "which manifests itself in the disavowal of economics and the accumulation of cultural and symbolic capital". She sees DJs as having been forced to adopt an entrepreneurial position which "marks a break with anti-commercial notions of creative activities". In invoking Bordieu's concept of Illusio, Reitsamer observes that "DJs' faith in the 'game' of recognition... puts the DJs in competition with one another in the struggle for a legitimate position in the music scenes" (2011: 38). While acknowledging that, for Bordieu, Illusio was characterized by economic disinterest, Reitsamer posited that DJs none the less saw creative success as a path to economic success, which was exhibited in the work dedicated to original music productions, remixing and label creation amongst the DJs she interviewed.

In a revealing study of local rock musicians in the late 1980s, Stephen B. Groce employed qualitative sociology to examine how the actors had "developed a complex ideology to rationalize and justify what they [were] doing” (1989: 405-6). In defining ideology as a set of "interdependent ideas, held by a social group..., which reflects, rationalizes and defends its particular social, moral..., political and economic institutional interests and commitments", Groce revealed that copy musicians (or cover bands) saw their role as workers, who show up to do their work at a club with an orientation to customer satisfaction and an expectation of appropriate compensation, while original musicians were far less willing to classify their role in relation to performance and their music, repeatedly explaining that the creative process was more important than live performance or generating income. Groce saw these local performers as operating in situations where they have little to no control so they found "a system of definitions and assumptions which organize lived experience". $\mathrm{He}$ summarized that "in addition to providing individual musicians with a system of definitions and assumptions which organize lived experience, ideologies function to organize and give meaning to collective social experience as well" (Groce 1989: 393-4, 406-7).

The contemporary DJ or producer is asked to be at once both an entertainer and artist. These dual demands of their practice confuse and conflate traditional entertainer/artist distinctions. In practically and rhetorically merging these practices DJs and producers have privileged their roles as artists over their function as entertainers first. More, they have defined their new relation to practice with terminologies that enforce and perpetuate their precarious position in the creative economy while at the same time giving away the value of their personal and professional networks, fueled through crowdsourced remix competition platforms, to companies and their marketers in the pursuit of both tangible and emotional responses from their audience and peers.

Clubs, companies and marketers encourage and demand producers' labour on social media to enlist their personal and professional networks in creative practice through remix competition platforms. In doing so, the businesses engaged with EDM communities gain recognition, an audience and income of their own on the backs of largely free remixing labour provided by the producers. Seeing themselves primarily as artists, DJs and producers engage others with their practice in calls for "support", a word that masks and reveals so much of the current ideology that operates in dance music practice. 


\section{DISCOURSES OF SUPPORT}

In examining the discursive legacy of support in relation to "support the troops" movements, Patrick G. Coy, Lynne M. Woehrle and Gregory M. Maney define discursive legacies "as well-established, repetitive, restrictive, and culturally recognized ways of talking and writing about a particular issue over time" (2008: 163). For the authors these discourses "have triumphed in the contention over the terms of public debate on a recurring issue", which "often roughly reflect existing power relations" (Coy, Woehrle and Maney 2008: 163-4). Roger Stahl observes that the notion of support has two major functions: deflection, "which is the redefinition of war from a struggle to attain an external objective to an internal struggle to save the soldier", and disassociation, "a discourse that conditions the image of the proper wartime citizen" (2009: 535). Stahl concludes that notions of support are used to "foreclose debate" rather than encourage its citizens to question a state's involvement in conflict (Stahl 2009: 535-36). The investigation into notions of support by these authors shows that the term has a legacy that deflects and disassociates rhetoric from a criticism of those in power toward a language that leaves no room to debate. The ongoing use of support in relation to the troops has transformed the term from that of lifting others up or bearing an expense to a word that forecloses debate and enforces stable power relations and legitimate particular agendas. For these researchers the antidote to foreclosed support rhetoric is to bypass these rhetorical devices and engage directly with those in power, to "valorize civic deliberation", and to direct attention back to questions of legitimacy (Stahl 2009: 559).

These investigations and proposals for change lie at the heart of my investigation of producers and their calls for support in relation to remix contests and competition platforms. While the stakes may not be as high as those of the military and armed conflict, support has none the less come to deflect and disassociate critical debates among creative workers from the structures of power that continue to exploit their creative labour from competition to competition. Although scholars have not examined links between the use of support in the militaristic sense and the use of the term in the creative sense, my experience in creative communities reveals that discourses of support among creatives and their networks reproduce the very same discursive legacy.

In examining the language of EDM networks it is clear the term "support" has gained significant currency in socially networked communications. Support is invoked by club owners, promoters, DJs, marketers and audiences on the ground and in social media to reflect their desire or need for assistance in relation to their participation in EDM. At a practical level rhetoric of support that surrounds creative practice is a key device in which artists and their stakeholders enroll each other in each other's creative networks. Calls for support that are involved in so much of creative rhetoric elegantly enlist other creatives in networks of practice but also serve to orient artistic practice outside structures of power that define their relation to labour in creative economies. Support, as a rhetorical device, both affirms membership in creative networks while also excluding others who choose to confront the real creative economy. If you do not support us we do not support 
you. We cannot support your push for financial reward, which necessarily sacrifices your creative integrity. Further these devices allow members of creative communities to engage with creative platform providers and aligned marketers while still justifying their position outside the precarious reality of contemporary creative economies.

Calls for support are often invoked to encourage other members of a participant's network to engage with her interests in advancing their creative careers. For club owners support is used to ask other DJs, producers and their audiences to engage with their club, through attending club nights or telling their networks about upcoming events. Promoters ask DJs and producers to support their night through participating as performers or through cross promoting each other's nights. DJs and producers will ask their audiences to support their performances at events, or support their productions or remixes by following links to media. Established producers support label releases in ongoing exchanges of branded marketing. Friends and fans of these owners, promoters and performers cast support nets even wider, invoking their own networks of friends and families to consider aiding their friends of colleagues. If the language in describing these various relations seems strained it is because the term and language of support has come to replace individuals in these circles. Owners become supporters of promoters and DJs. Promoters support the clubs with their talent, the DJs they support. DJs are surrounded with support and supporters. While there are clearly structures of power in EDM, in these associations the rhetoric of relations are made horizontal, all under the rubric of support.

\section{CONTEMPORARY REMIX CONTESTS}

Contemporary competitive remix practices among creatives in EDM is almost entirely facilitate by crowdsourced competition platforms. These platforms both facilitate and encourage competition with and among creative networks on the web and in local venues. By developing neutral platforms that integrate deeply with social media to provide creative competition these websites represent a significant evolution in crowdsourcing development that threatens the definitional and ethical boundaries of the practice. Where traditional crowdsourcing platforms transmit a problem to the crowd for a solution that usually results in the manufacturing of a product or idea these competition platforms crowdsource creativity and creative networks in the service of enmeshing those individuals and their audiences with the contest brands, while often providing little reward other than nominal compensation and vague promises of exposure. Further, these platforms and related marketers usually require that remix producers sign away the rights to their work when entering the contests, while generally discarding the vast majority of submitted creativity and rarely doing much with winning entries beyond the limited terms set out in the call for submissions. For these platforms and their partners creativity only matters as long as it leads to another share or another like. As a result remixes are often reduced on these platforms to a vector for generating a few extra twitter followers and a few more hits on a brand's YouTube channel. ${ }^{9}$ 
Despite these developments DJs and producers and their networks seem all too eager to engage with remix contest platforms as a chance to find exposure for their creativity. Rather than examine their role in these contests and the vast exploitation involved in the process of these competitions, remix producers are all too willing to join in on the contest as a path to creative success. Further DJs and producers are driven to do so by institutions that surround them who often lean on crowdsourcing platforms to provide the most talent at the lowest possible cost, with local labels and clubs often demanding that their workers engage with crowdsourcing platforms to help expose their local brands to the socially-networked communication these contests platforms provide.

While competitions would not necessarily be harmful if smaller practitioners were partners in these exchanges, the entire practice of DJing and remixing has shifted toward free competition and labour as a way of producing marketable exchange rather than through investment and development that factors in the basic rights and necessities of creative workers. Rather than making demands of these remix contest websites or turning away from these large marketers and labels, local DJs and producers are creating more and more for those powerful actors in the hopes of making it big. To be clear, for many, if not a majority, of these performers working in contemporary club networks, "making it big" is analogous to being rich and famous as a music producer and DJ, though this notion is rarely expressed in terms beyond those of reaching a certain creative potential as an individual artist.

The drive to make it big through remix competitions is aided by established EDM celebrities who often partner with labels and marketers on various competition platforms to encourage the continued competing of local DJs and producers with the promise that they too could be the next superstar DJ. Afrojack, a popular DJ and producer who has found commercial success in EDM circles, serves as an example of how celebrity aids in popularizing remix contests while also mystifying their own role and the role of marketers in the creation and distribution of competition on crowdsourcing platforms. Throughout Afrojack's career he has enlisted the term "support" to propel his music career, his brand and related businesses while mystifying his relation to EDM and labour. Afrojack regularly expresses his gratitude for support from friends and colleagues through his social media presence on Twitter and Facebook. In an interview with Rolling Stone in the lead up to his October, 2013 release of The Spark, Afrojack reflected on his association with David Guetta, a French producer and major EDM mover and shaker: "Support like this is everything to an artist on the way up and he inspired me to want to give back in the same way to others... I worked hard for it, but it can happen to you if you really want it" (Luerssen 2013). Afrojack often uses the term support to indicate he will play forthcoming tracks of other music producers, a common practice among DJs at local and international levels (Spinnin Records 2013). Support is often invoked by Afrojack to indicate other DJs and producers that are performing alongside him at various clubs and festivals (Afrojack 2013a). His label has offered remix and video production contests through Beatport and Genero. $\mathrm{tv}$, claiming to support creative communities and find unique talent (Beatport 2011). The calls for support often engage local producers and their audiences who are directed toward 
Afrojack's associated websites to engage with the performer in echoing his calls for support or by entering related remix contests.

Nowhere in Afrojack's social media presence and related media are there explicit references to structures of money and power that flow through EDM practices. Calls for support in these cases often mask the very real relations to capital that flow through Afrojack and his brands. Instead of being supported by other producers, such as David Guetta, Afrojack had entered creative partnerships where he was initially and likely remains, an unequal member (Afrojack 2013b; Gensler 2013). These partnerships produce creative works that are bought and sold among major and minor labels as real exchanges for real money. Afrojack has leveraged his relative power in dance music economies to sign producers and remixed productions to his label, amassing a portfolio of creative works that he markets and sells. Invoking support in relation to releases on partnered labels is a cross-promotional practice that associates various producer brands with releases similar to the way major corporations have a portfolio of starts they use for promotion of their brands. By lending his name to these releases, Afrojack invites his fans, venues, producers and labels to engage with other producers and brands along with the marketers of various labels and the platforms that are ready and willing to sell these tracks to enthusiastic audiences. Enlisting ideas of support in relation to other performers at his live events masks an entire range of complex negotiations that are involved in most major performance contracts. Are these supporting DJs and producers part of Afrojack's requirements to perform; do they include local talent, or perhaps a contest winner? In supporting Afrojack, are these supporting artists being paid to perform or do they give away their labour in the hope of gaining notoriety, through association with Afrojack and his networks, as a reward? Clearly in many of these situations the relations operate barely under notions of support, but it is the continued reluctance to acknowledge these associations by DJs and producers across EDM that is so striking.

Multiplied by the thousands of notable DJs and producers currently working in EDM and their expansive networks, which includes their audiences, labels, marketers and countless websites, it reveals a striking separation from the reality of economy and creative labour that are at the heart of their day-to-day practices. For the hundreds of thousands of DJs working across local networks, notions of support mystify and exploit creative practice across EDM.

\section{local Engagement with Remix Competition Platforms: A Case Study}

My case study of a 2013 Beatport Play remix competition and the discourses of support that mobilized local DJs and producers to engage with the contest website is a direct result of my own participation in an earlier club competition in the spring of that same year. My placement in that club competition in Montreal, Quebec "won" me access to regular meetings at the venue, which were assembled to engage local DJs and promoters in the promotion of future events. What I witnessed in these meetings and what is detailed below was a confirmation of similar discussions and actions surrounding remix competitions that I witnessed as a working DJ in Calgary, Alberta. 
On Thursday, December $5^{\text {th }}, 2013$, a monthly DJ meeting was held at Circus Afterhours to discuss recent developments at the club and talk over upcoming events. Circus, a Montreal afterhours club and oft-rated number one dance venue in the province of Quebec by industry magazines and websites, was preparing to host the biggest event in its history, the Circus Maximus New Year's party that was planned for December $31^{\text {st }}$. The party would use all available club space to pack 1600 revelers into the venue with tickets for entrance priced anywhere from $\$ 65$ up front to $\$ 95$ at the door. The meeting of DJs at Circus centred on issues of promotion and sales for the event. Of the forty resident DJs-that is, DJs who perform at Circus approximately once a month-twenty arrived to hear the pitch. Twenty three DJs were scheduled to play between three rooms on New Year's Eve. Of those, some were Circus residents while others were national or international DJs and producers flown in for the night. The remaining DJs were asked to sell tickets for the event in support of the club. The justification was that by supporting the club's promotion of the biggest event of the year all DJs engaged in some way with Circus would benefit in key ways. First, the event's success would help sustain the club and allow them to bring in more acts. Second, it would allow Circus Afterhours to further support local DJs through increased notoriety and the opening of secondary rooms on a regular basis. "Support us as we support you" was an oft-repeated refrain from the primary promoter and many young and enthusiastic resident DJs, who insisted that, by freely promoting ticket sales for the event, all DJs would benefit. In addition, the promoter encouraged all DJs to produce and remix music with the goal of spreading the productions across music hosting and promotion websites and social media. The idea was that if Circus DJs were exposed and recognized in wider EDM markets, then Circus Afterhours would benefit similarly.

In asking for support through production and remix, the promoter, as an employee of Circus, was asking for a significant amount of free labour, from a precarious workforce of tangentially connected DJs and producers, to promote for shows that many were not working as performers or entertainers. Further, petitions for support came with a warning that if these DJs did not respond to the request, their status as a resident could be in jeopardy. Rather than explicit communication over expectations of work at the club and remuneration, the promoter chose instead to speak in vague terms of growing communities of DJs and producers.

While Circus spent lavishly on promotional banners, print and web advertising for the New Year's event, a far cheaper, more personal and efficient promotion machine was engaged when the resident DJs of Circus and their networks of friends and fans took to Facebook, Twitter and Beatport to market Circus Afterhours and the New Year's event. Most made individual posts on their personal pages and fan pages - a common practice amongst local DJs and producers, which is used to provide information to a wider audience about their shows and releases-along with engaging Twitter to spread information about the event. The local DJs enlisted for one hour sets at the New Year's event, with the agreement they would be paid a nominal amount of money, were sent special digital posters and banners to replace their Facebook/Twitter profile pictures and cover photos. Similar generic graphics 
were sent out to individuals closely associated with Circus, encouraging them to support the club by promoting alongside them.

Calls for support rang out on social media, promoting Circus and the New Year's Eve party. Resident DJs asked for support by having their audience attend their performance on the night, while other unscheduled DJs asked for their friend and fans to attend the event in support of their club. Many resident DJs took up the second promoter request and either began or searched out new remix opportunities in the hopes of engaging and growing their own professional network along with the clubs. While producers associated with Circus released tracks on a regular basis, either for free on social media or through various local labels on Beatport, a particular remix contest, hosted on Beatport Play, enrolled a number of Circus DJ/producers into a competition that translated the support of local EDM networks into web impressions and revenue for the competition platform and its related labels and marketers.

The remix contest for Tiga vs. Audion, Let's Go Dancing, appeared in early November following the original's release to Beatport and ITunes in mid-September 2013 (Beatport 2013e). Beatport News released contest details asking DJs to "join the ranks of hot-hand producers like Maya Jane Coles, Breach and Solomun, among others, who've been tipped to remix Tiga vs. Audion's single, Let's Go Dancing, on Turbo Recordings" (Black 2013). Beatport news encouraged DJs and producers to imagine themselves "alongside like-minded label artists like Duke Dumont, Azari \& III and Clouds" (Black 2013). The website offered audio stems for download and asked DJs to upload their remix to play.beatport.com for a chance to win various DJ related technologies along with a "bonus" release of the track on the contest's host label.

By the submission deadline on December ${ }^{\text {th }}, 2013,560$ remixes of Let's Go Dancing had been uploaded to Beatport's servers. Remixes ranged in style, length and production quality, but all were represented through Beatport Play's algorithms as greyscale rectangles sorted on a list down the webpage with a voting button, comment section and hot linking to the producer's DJ page that contained a history of their activity on the site. The website translated the character and quality of individual creative productions into a bar of exchange that could be moved up and down as if they were entries on an accounting ledger. As the contest progressed votes slowly rolled in, moving entries up and down the list as producers enlisted their audiences to visit the Beatport site and vote. Comments were left on the website in support or in critique of the various entries, which were often closely monitored and responded to by the entrants and their fans.

Despite a lack of guarantees that top entries would be even considered for the grand prize, with the contest offering only a smaller prize to the entry with the most votes, DJs enthusiastically spread the remix contest links and information around their social media pages and contacts. Even with the lack of guarantees it is generally accepted in EDM contest networks that only the top few vote-getting entries will be considered, as the number of people producers are able to send to these contest sites are a major factor in the selection 
process. The potential to have those votes translated into music sales for the label through Beatport is very persuasive for labels that rely on the sale of digital files as a major source of income.

No less than four Circus residents submitted remixes as part of the Let's Go Dancing contest. Throughout the submission and voting process calls for support rang out on Facebook and Twitter. Scott James, a house DJ at Circus, posted his remix to both his Facebook personal and Facebook fan page. His call for votes was in relation to a number of posts he curated attempting to position him as a serious producer. Many posts were made over successive days attempting to engage his supporters to vote for his submission. Scott James's contest page was shared on social media no fewer than 98 times over a two month period (Beatport 2013a). Despite the considerable number of links James's submission was listened to only 185 times, garnering 13 votes. Marc Luciano, a deep house specialist at Circus, regularly posted his contest link with calls for support; "Our track is chilling on the first page right under the tracks of the people who have been spamming to get votes. If you haven't voted, check out the track and if you like it, your support would mean so much! REPRESENT MTL" (Beatport 2013b). Luciano was nominally successful, garnering over 500 plays of his remix along with 48 votes, despite sharing his link far fewer times than other Circus residents. Joe Mesmar, a resident techno DJ at Circus, submitted to the contest and engaged his web of social media contacts a number of times with calls for support. "Take a listen \& vote for me if I deserve it! Thanks to every person who's supporting me! Not asking for more" (Beatport 2013d). ${ }^{10}$ Mesmar was able to translate calls for support into a significant number of votes and by contest end had well over 1300 plays, 120 comments and critiques and the most votes in the contest.

For Circus Afterhours, the exposure of its DJs and producers through social media and contest platforms is a vector for free promotion and sales of New Year's Eve tickets in addition to other events. For the producers involved in the contest, it is a way of promoting their own brand while engaging their audiences, the club promoters and Beatport labels in cross networking and promotion. While goals of wider exposure and more performances at Circus are more immediate, the aim for fame and improved economic status operate beneath every Facebook share or tweet. Turbo recordings and the label owner Tiga, have been provided with over 500 remix submissions, which represent hundreds of hours of work, thousands of dollars of sunken technology costs and the emotional and intellectual engagement of hundreds of producers and thousands of individuals in their personal and professional networks. Despite the costs in hours, money and promotion involved in these contests and the eventual expectation of creative or economic reward, the dialogue in and amongst those involved remains couched in notions of charity and support. While Afrojack continues to recall his humble beginnings and encourages anyone who will listen that we all have the spark, Beatport and its partners gather up competitive exchanges and package them into content portfolios that add to their parent company's, SFX Entertainment, bottom line. 


\section{CONCLUSION}

The rapid development and dissemination of remix competition platforms have led to immediate shifts in the practices of DJs and producers online and on the ground. For professional DJs and producers these remix contest websites have had a significant impact on how they practice their craft. Contest websites have reoriented certain practices into networks of competition, where creatives and their audiences are asked to engage with these platforms and their partners for a chance to sign away their work if they happen to be "lucky" or "talented" enough to win a remix contest. Winning distinction in these contests is often only part of a larger process of further enmeshing DJs and producers and their networks of supporters in the ecosystems that these platforms have created. Having rationalized competition as a largely positive phenomenon, the contemporary EDM producer and her web of connections is ready and available to serve remix contest after remix contest as required, as competition is the fuel that sustains it. Extrapolating these remix competition processes across the enormous and expanding numbers of talent contests available points to a significant exploitation of creative labour.

These competition and marketing platforms have moved to exploit the relatively high number of DJs and producers willing to compete in contests by selling the notion that competing is one of the few ways to gain exposure, while the participating labels also benefit from receiving a competition product they can promote and exploit for their own gain, which also ensures competitors conform to a relatively rigid set of remix production expectations. Frequent and widespread competitions are supplied by large reservoirs of free labour. Music download sites then sell these remixed products back to the producers and their networks, expecting that their audiences will buy a product that includes their friend's creativity. While a producer may benefit from the chance to perform or have their remix released commercially in some ways, the costs and expectations of these contests, especially when multiplied by the manifold contestants involved, often far exceed the value gained by producers as individuals or as a whole. With relatively little to gain by individual DJs and producers competition to competition, event to event, platform to platform, a stable supply of regenerating contesting labour will be available for subsequent remix contests, which often ask the same workers to compete once more for a chance to show their "unique" talent.

In examining the rise of competitive practices in creative economies through the lens of DJs, producers and the remix contest platforms they compete on, I have sought to reveal the web of relations that produces the precarious reality of contemporary creative workers. It is an examination that seeks to be part of a larger discussion of the reconfiguration of labour in contemporary creative economies driven by evolutions in technologies and fueled by shifts in discourse that seek to rationalize and valorize competitive practice as the best way for artists to unlock their hidden talents and become another productive member of "Me Inc" (Hearn 2008).

In The Precariat, Guy Standing notes that, through the encouragement of competitive practices, businesses were deliberately transferring risk to the worker under "fictitious 
decommodification" (2011: 41). The transfer of risk "means an advantage for employers and increased risk and insecurity for wage earners" (Standing 2011: 43). In doing so these companies were making the lives of workers more precarious. By following the discourses of local DJs and producers and stripping away the mysticism that surrounds their competitive practice, it is clear that clubs, labels, web platforms and partner brands are transferring many of the risks of operating in contemporary creative economies onto their workers. In promoting, assembling and performing competition after competition, DJs and producers, along with artists in many creative fields were left to do most of the work with very little compensation. Despite their exploitation, artists seem to generally revel in the opportunity to create for the opportunity for exposure and a chance at fame. There is a turning inwards of rhetoric and practice where creatives continually compete with each other over what precious little work is available instead of contesting the overriding labour practices maintained by local venues and online platforms that have gutted traditional creative employment opportunities. Furthermore creatives are often encouraged to bring their networks to the table in a cyclical generation of competitive practices. Having rationalized competition as a largely positive phenomenon, contemporary creative networks are ready and available to serve contest after contest as required, as competition is the fuel that sustains it.

By providing competitive venues for marketers to exploit social media communications these platforms are more advertising agencies than talent scouts. As marketing forces these companies are taking advantage of a largely unregulated marketing space, the contemporary social media connected web, to promote their brand partners on the backs of precarious creative labour. In injecting brands into creative communication these companies are breaking a number of principles and best practices that marketers are required to adhere to in traditional marketing space. They are able to bypass these regulations by shrewdly masking their branded exploitations behind discourses of creative exposure and support. Their promises are not backed up by reality as the vast majority of remix producers engaged in competition receive little benefit. Brand partnerships and their objectives are masked behind throw-away prizes and promises of celebrity to attract many artists as possible. By not disclosing their role as marketer first these platforms are extremely unethical. It is my hope that by paying increased attention to these sites that the majority of their practices will eventually require greater disclosure if not a complete reworking.

There is no sign that these competitions will enter into decline in the near future. There is a virtually endless stream of young and influential talent that will continue to enter various contests in the hopes of breaking into full-time DJ work. Venues and marketers will continue to mobilize and mediate these networks then drop them once they stop providing enough value to their businesses. Major competition networks across the globe will continue to legitimize competitive practice through a filter of sponsorships that will continue to encourage certain practices over others in the interest of their branding. The creative worker will continue to struggle from contest to contest expending large physical and mental energies producing and promoting enough networked value to gain a foothold in a small part of the creative economy. 
For DJs and producers there is solace in the performative aspect of their craft. Despite the expansion of web-based practices DJs and producers are in greater demand than ever before. Even though their creative practices increasingly include web platforms, a great deal of what makes a EDM network tick is still in the material reality of local spaces and peer-to-peer communication. As the rapid expansion of EDM practices cools, my hope is that increased attention will be paid to the material and historical connections that make creative practice what it is, as well as the problematic discourses that activate and enable exploitation in dance music economies.

\section{ACKNOWLEDGMENTS}

I would like to thank Dr. Will Straw for helping guide and translate my passion for DJing into scholarly terms. I would also like to thank Dr. Darin Barney, Dr. Jonathan Sterne and Matt Stahl for their advice. Further I would like to thank Anne Pasek, a fellow McGill student. She is both a brilliant scholar and a wonderful person.

\section{NOTES}

1 See Farrugia (2010), Montano (2010), Reynolds (2010), Attias (2011), Attias and Veen (2011, 2012), Ahmed, Benford and Crabtree (2012).

2 Crowdsourcing is a way of describing the rise of web-based practices in the last fifteen years whereby organizations began to outsource labour to the open market (the crowd) through web based platforms, in hopes of tapping a vast network of talent and ingenuity to provide solutions to their organizational problems (Brabham 2008a; Geiger et al. 2011; Guittard and Schenk and 2011).

3 Creative competition platforms centre their businesses on the use of social media to leverage the work of painters, designers, filmmakers, music producers, photographers and programmers. These are all part of a group of workers I will describe as creatives or the creative class (Florida 2002; Peck 2005).

4 Facebook Connect was launched in 2008 and was quickly adopted by thousands of websites to provide a login service that could be used to easily connect to other websites using Facebook credentials (Jefferson 2009).

5 Remix contests in EDM often involve the release of 'stems', that are samples used in the production of a track. In remix competitions audio segments used in an original recording, often including, percussion, vocal tracks and synths, are made available on contest hosting websites for download by competitors. These audio pieces or "stems" are offered so that they 
can be remixed by music producers into alternative versions of the original song. While most competitions provides these audio pieces for free, some contest websites charge nominal fees for their download.

6 An early failed example was a Chevy marketing campaign (Bosman 2006).

7 A significant amount of qualitative interview-based research has been done on EDM networks. This research has often involved questioning DJs, producers, promoters, club owners and audiences. Further, interview-based researched has also been used to examine social media communities and participants on crowdsourcing websites. Despite the extensive use of interviews by many of the researchers, papers and books that inform my own research on competitive labour, this method is not sufficient to get at the heart of the issues surrounding these new competition practices. Primarily my research attempts to examine and give voice to the thousands of DJs and producers entering creative contests globally. Most of the available interview data suggests that the winners are often the only ones available or sought out to be consulted in studies of these platforms, despite their specificity as high-profile members of the networks and a minority of total contest participants (Heinrich 2014).

8 DVS stands for Digital Vinyl System. Major players in the DVS market are Serato, with their Rane hardware based Scratch live software and Native Instruments, with the Traktor hardware and software solutions. Many competitors sell a range of midi solutions, ranging from small controllers that compliment DVS systems to entire performance setups in a box. Midi, or Musical Instrument Digital Interface is a protocol that allows electronic music instruments and computers to communicate with each other.

9 Almost every scholar who has written about crowdsourcing has examined it effect on workers who participate or who might have worked in related industries before their development. As an example, Brabham has examined how iStockphoto and related sites has virtually wiped out traditional stock photography businesses (Brabham 2008b; Howe 2006).

10 Post made to Joe Mesmar's fan page (Mesmar 2013).

\section{REFERENCES}

Afrojack. 2013a. "Afrojack Facebook". Facebook. (accessed December 22 2013). < $\underline{\text { https://www. }}$ facebook.com/djafrojack $>$.

- _ . 2013b. "Yessir! EDM took over Time Square and the Nasdaq today!" Instagram. (accessed December 22 2013). <http://instagram.com/p/fRHwFsItBm>.

Ahmed, Ahmed, Steve Benford and Andy Crabtree. 2012. "Digging in the Crates: An Ethnographic Study of DJS’ Work “. Austin (Texas): Association for Computing Machinery Special Interest Group on Computer-Human Interaction Conference.

Attias, Bernardo Alexander. 2011. "Meditations on the Death of Vinyl". Dancecult: Journal of Electronic Dance Music Culture 3(1). < http://dx.doi.org/10.12801/1947-5403.2011.03.01.10>. 
Attias, Bernardo Alexander, and Tobias C. van Veen. 2011. "Off the Record: Turntablism and Controllerism in the 21st Century, (Part 1)". Dancecult: Journal of Electronic Dance Music Culture 3(1). < http://dx.doi.org/10.12801/1947-5403.2011.03.01.08>.

_- - 2012. "Off the Record: Turntablism and Controllerism in the 21 st Century (Part 2)". Dancecult: Journal of Electronic Dance Music Culture 4(1). < https://dj.dancecult.net/index. $\mathrm{php} /$ dancecult/article/view/332/328>.

Baker, Sarah, and David Hesmondhalgh. 2013. Creative Labour: Media Work in three Cultural Industries. New York: Routledge.

Beatport. 2011. "Announcing Afrojack and Quintino's Selecta Remix Contest”. Beatport. (accessed December 27 2013). <http://news.beatport.com/blog/2011/06/14/ announcing-afrojack-and-quintinos-selecta-remix-contest/> .

- - - 2013a. "LET'S GO DANCING (SCOTT JAMES \& TWEAK\&BRAINS REMIX)”. Beatport. (accessed December 28 2013). < http://play.beatport.com/contests/ tiga-vs-audion-lets-go-dancing/52a4f9b3753a0d72b9b1a998 >.

- - - 2013b. "LETS GO DANCING (THOSEGUYS FROM MTL REMIX)". Beatport. (accessed December 28 2013). < http://play.beatport.com/contests/ tiga-vs-audion-lets-go-dancing/52a5079cb8ed74474677770e $>$.

_- _. 2013c. “Tegan \& Sara Closer Remix Contest”. Beatport. (accessed December 212013 ). $<$ http://play.beatport.com/contests/tegan-sara-closer $>$.

———. 2013d. “TIGA VS AUDION - LET'S GO DANCING (JOE MESMAR REMIX)”. Beatport. (accessed December 28 2013). < http://play.beatport.com/contests/ tiga-vs-audion-lets-go-dancing/529cf593753a0d72a972ca82>.

- - - 2013e. “Tiga vs. Audion: Let's Go Dancing Remix Contest”. Beatport. (accessed December 28 2013). < http://play.beatport.com/contests/tiga-vs-audion-lets-go-dancing>.

Black, Jason. 2013. “This Week on Play: Win DJ Gear from Novation and get Released on Turbo Recordings in Tiga vs. Audion's 'Let's Go Dancing' Remix Contest “. Beatport. (accessed December 25 2013). <http://news.beatport.com/blog/2013/11/12/this-week-on-playwin-dj-gear-from-novation-and-get-released-on-turbo-recordings-in-tiga-vs-audions-lets-godancing-remix-contest>.

Bosman, Julie. 2006. "Chevy Tries a Write-your-own-ad Approach, and the Potshots Fly". New York Times, 2 April 4.

Brabham, Daren C. 2008a. "Crowdsourcing as a Model for Problem Solving an Introduction and Cases". Convergence: the International Journal of Research into New Media technologies 14(1): 75-90. < http://dx.doi.org/10.1177/1354856507084420>.

- - 2008b. "Moving the Crowd at iStockphoto: The Composition of the Crowd and Motivations for Participation in a Crowdsourcing Application”. First Monday 13(6). <http://dx.doi.org/10.5210/fm.v13i6.2159>.

—— - 2013. Crowdsourcing. Cambridge: Massachusetts Institute of Technology Press.

Coy, Patrick G., Lynne M. Woehrle and Gregory M. Maney. 2008. “Discursive Legacies: The U.S. Peace Movement and "Support the Troops". Social Problems 55(2): 161-89. < $\underline{\text { http://dx.doi. }}$ org/10.1525/sp.2008.55.2.161>. 
Farrugia, Rebekah. 2010. “'Let's Have At It!' Conversations with EDM Producers Kate Simko and DJ Denise". Dancecult: Journal of Electronic Dance Music Culture 1(2): 87-93.

$<$ http://dj.dancecult.net/index.php/journal/article/view/38/47>.

Florida, Richard L. 2002. The Rise of the Creative Class: and How it's Transforming Work, Leisure, Community and Everyday Life. New York: Basic books.

Gamson, Joshua. 2011. "The Unwatched Life Is Not Worth Living: The Elevation of the Ordinary in Celebrity Culture". Publications of the Modern Language Association of America 126(4): 1061-9. <http://dx.doi.org/10.1632/pmla.2011.126.4.1061>.

Geiger, David, Stefan Seedorf, Thimo Schulze, Robert C Nickerson and Martin Schader. 2011. "Managing the Crowd: Towards a Taxonomy of Crowdsourcing Processes". Detroit (Michigan): Association for Information Systems Conference.

Generto.tv. 2013. "Moby Make the Official Video for Almost Home”. Genero.tv. (accessed December 21 2013). <http://genero.tv/almosthome/>.

Gensler, Andy. 2013. “Robert F.X Sillerman On SFX's IPO, Stock Prices, Future Acquisitions, Afrojack”. Billboard (accessed December 10 2013). <http://www.billboard.com/biz/articles/ news/legal-and-management/5755260/robert-fx-sillerman-on-sfxs-ipo-stock-prices-future $>$.

Groce, Stephen B. 1989. "Occupational Rhetoric and Ideology: A Comparison of Copy and Original Music Performers”. Qualitative Sociology 12(4): 391-410. <http://dx.doi.org/10.1007/bf00989399>.

Guittard, Claude, and Eric Schenk. 2011. “Towards a Characterization of Crowdsourcing Practices". Journal of Innovation Economics \& Management (1): 93-107. < http://dx.doi.org/10.3917/jie.007.0093>.

Hearn, Alison. 2008. "Meat, Mask, Burden: Probing the Contours of the Branded Self ". Journal of Consumer Culture 8(2): 197-217. <http://dx.doi.org/10.1177/1469540508090086>.

Heinrich, Julia and Carsten Winter. 2014. "The Added Value to Music Culture through Collaborative Online Platforms”. Círculo Universitário do Porto (Portugal): Keep It Simple Make It Fast Conference.

Howe, Jeff. 2006. “The Rise of Crowdsourcing”. Wired, June: 1-4.

- - 2008. Crowdsourcing: How the Power of the Crowd is Driving the Future of Business. New York: Random House.

Jefferson, Graham. 2009. “Facebook Connect makes Signing into your Sites Fast”. USA Today, 15 April: B5.

Luerssen, John D. 2013. “Afrojack Pays Tribute to Mentor David Guetta: DJ releases last installment of March of the Afrojack". Rolling Stone (accessed December 27 2013). <http://www.rollingstone.com/music/videos/ afrojack-pays-tribute-to-mentor-david-guetta-20131023 >.

McRobbie, Angela. 2002. "Clubs to Companies: Notes on the Decline of Political Culture in Speeded up Creative Worlds”. Cultural Studies 16(4): 516-31.

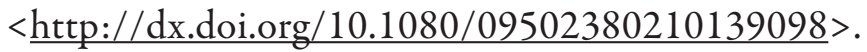

- - - forthcoming. Be Creative? Making a Living in the New Culture Industries. Cambridge: Polity.

Mesmar, Joe. 2013. “Joe Mesmar Fan Page”. Facebook (accessed December 30 2013). <https://www.facebook.com/JoeMesmarOfficial>. 
Montano, Ed. 2009. "DJ Culture in the Commercial Sydney Dance Music Scene". Dancecult:

Journal of Electronic Dance Music Culture 1(1): 81-93. <http://dx.doi.org/10.12801/1947-5403.2009.01.01.05>.

- - - 2010. “ How Do You Know He's Not Playing Pac-Man While He's Supposed to Be DJing?: Technology, Formats and the Digital Future of DJ Culture”. Popular Music 29(3): 397-416. < http://dx.doi.org/10.1017/S0261143010000449>.

_- - 2011. "Festival Fever and International DJs: The Changing Shape of DJ Culture in Sydney's Commercial Electronic Dance Music Scene”. Dancecult: Journal of Electronic Dance Music Culture 2(1): 63-89. <http://dx.doi.org/10.12801/1947-5403.2011.02.01.04>.

_- _. 2013. "Ethnography From the Inside: Industry-based Research in the Commercial Sydney EDM Scene”. Dancecult: Journal of Electronic Dance Music Culture 5(2): 113-30. $<$ http://dx.doi.org/10.12801/1947-5403.2013.05.02.06>.

Peck, Jamie. 2005. "Struggling with the Creative Class". International Journal of Urban and Regional Research 29(4): 740-70. < http://dx.doi.org/10.1111/j.1468-2427.2005.00620.x >.

Reitsamer, Rosa. 2011. “The DIY Careers of Techno and Drum 'n' Bass DJs in Vienna”. Dancecult: Journal of Electronic Dance Music Culture 3(1): 28-43. <http://dx.doi.org/10.12801/1947-5403.2011.03.01.02>.

Reynolds, Simon. 2010. “The History of Our World: The Hardcore Continuum Debate”. Dancecult: Journal of Electronic Dance Music Culture 1(2): 69-76. <http://dx.doi.org/10.12801/1947-5403.2010.01.02.05>.

Ross, Andrew. 2009. Nice Work If You Can Get it: Life and Labor in Precarious Times. New York: New York University Press.

Spinnin Records. 2013. "Leon Bolier - Disco Davai (Official Music Video)”. (accessed December 27 2013). Facebook. < https://www.facebook.com/SpinninRecords/ posts $/ 682305188462055>$.

Stahl, Matt. 2012. Unfree Masters: Recording Artists and the Politics of Work. Durham: Duke University Press.

Stahl, Roger. 2009. "Why We 'Support the Troops': Rhetorical Evolutions”. Rhetoric \& Public Affairs 12(4): 533-570. <http://dx.doi.org/10.1353/rap.0.0121>.

Standing, Guy. 2011. The Precariat: The New Dangerous Class. New York, NY: Bloomsbury. Talenthouse Inc. 2013. "Photograph for the Thomson Reuters Foundation \& Nokia Photo Award”. Talenthouse. (accessed December 21 2013). <http://www.talenthouse.com/ photograph-for-thomson-reuters-foundation-and-click-4-change $>$. 